\title{
Erratum to: A spatio-temporal three-dimensional conceptualization and simulation of Dera Ismail Khan alluvial aquifer in visual MODFLOW: a case study from Pakistan
}

\author{
Anwar Qadir ${ }^{1}$ - Zulfiqar Ahmad ${ }^{2}$ - Tahseenullah Khan ${ }^{3}$ - Mohammad Zafar ${ }^{3}$. \\ Atwar Qadir ${ }^{4}$. Mamoru Murata ${ }^{5}$
}

Published online: 1 June 2016

(C) Saudi Society for Geosciences 2016

Erratum to: Arab J Geosci

DOI: $10.1007 / \mathrm{s} 12517-015-2069-\mathrm{Z}$

The original version of this article, unfortunately, contained errors.

In the authors' affiliations, numbers 2 and 3 addresses were interchanged.

Correct affiliations 2 and 3 are:

${ }^{2}$ Department of Earth Sciences, Quaid-e-Azam University, Islamabad, Pakistan

${ }^{3}$ Department of Earth and Environmental Sciences, Bahria University, Shangrilla Road, Sector E-8, Islamabad, Pakistan

These are also reflected in the complete list of affiliations in this article.

The online version of the original article can be found at http://dx.doi.org/ $10.1007 / \mathrm{s} 12517-015-2069-\mathrm{z}$

Anwar Qadir

qaq212001@hotmail.com

1 Department of Geology, University of Haripur, Hattar Road, Haripur, Pakistan

2 Department of Earth Sciences, Quaid-e-Azam University, Islamabad, Pakistan

3 Department of Earth and Environmental Sciences, Bahria University, Shangrilla Road, Sector E-8, Islamabad, Pakistan

4 Department of Basic Sciences, Riphah International University, Islamabad, Pakistan

5 Department of Geosciences, Faculty of Science, Naruto University of Education, National University Corporation,

Naruto, Tokushima 772-8502, Japan 